\title{
Numerical Simulation Research on Rigid-flexible Piles
}

\author{
Xiude CAI \\ School of Civil Engineering \\ University of South of China \\ Hunan, China \\ e-mail: 657500206@qq.com
}

\author{
Wenzhao CHEN \\ School of Civil Engineering \\ University of South of China \\ Hunan, China \\ e-mail: 756258433@qq.com
}

\begin{abstract}
The rigid long piles and flexible short piles which under the free state has carried out system test, firstly it has carried on the pile body completeness inspection before test, then to carry out the free state of rigid pile and flexible pile and composite foundation static load test of pile type respectively. The bearing capacity of composite foundation with three cases of mechanism has carried on the comparative analysis, through the experimental study on the scene in regard to more type pile composite foundation and the free state of the stress and displacement of single pile foundation, analysis of pile composite foundation can better understand the understanding of the mechanism of action and give a correct evaluation of actual project.
\end{abstract}

Keywords-numerical simulation; rigid-flexible pile; composite foundation; static load test

\section{INTRODUCTION}

Artificial foundation treatment method is commonly used in surface layer soil cushion method, heavy hammer compaction and dynamic compaction and vibroflotation, sand pile, pile, deep mixing, compaction methods of load preloading, chemical reinforcement, these traditional methods of ground treatment is difficult to meet the requirements of technology, economy, environmental protection, etc. Each method has some limitations. Many pile type refers to the use of short rigid pile, flexible pile and soil between piles as a whole under the effect of stress conditions through the deformation coordination and achieve collaborative interdisciplinary foundation under external load. More type pile composite foundation can change the strength, stiffness and the distribution of vertical form to adapt to continuously reduce the additional stress from top to bottom features, complex foundation treatment technology was more and more widely used in many engineering [1 3].

Domestic and foreign relevant scholars both in theory and in experiment are much mechanism of pile composite foundation has done some research work. Guo zhiqiang (2003) [4] in collapsibility have poor geological conditions, through the adoption of CFG pile and a combination of rammed soil-cement piles composite foundation, so as to effectively overcome the lower part of the foundation soil collapsibility of the problem. Yan Mingli (2003) [5] many examples of engineering pile composite foundation is studied, and the many type pile composite foundation is pointed out that not only can reduce the lower part of soft ground problem of collapsibility of soil properties, and can obtain higher bearing capacity of foundation. De-quan zhou (2004)
[6] pointed out that many pile composite foundation in the practical process to consider the size of the load, the base type, foundation soil conditions and the requirements of environmental protection, economic and reasonable selection of pile body material and construction method, process, pile body size and layout, etc, make the foundation and basis are meet the requirements of strength, deformation and stability. In the aspect of software simulation, Bransby. M. Springman, s.m [7] (1996) by three-dimensional finite element analysis of pile-soil composite foundation were studied, and the numerical analysis results with the centrifuge model test results, the experimental result is consistent with simulation results. Before MAO, xiao-nan gong [8] (1997) through the cavity expansion theory to get the pile top reverse Pierce the size of the amount of cushion and mattress layer between, just flexible pile body, pile soil modulus is a relationship between these three.

To sum up, the theoretical achievements of type pile composite foundation has farther lag behind the engineering practice, the understanding of many type pile composite foundation is still very superficial. Understanding of how type pile composite foundation and in improving bearing capacity to reduce the foundation settlement than other types of composite foundation are insufficient knowledge of the respect such as the advantages of, so to carry out the single pile vertical compressive static load test and static load test of pile composite foundation study provide the basis for design and construction of $\mathrm{f}$ is imperative.

\section{LENGTH OF PILE SuCH AS LONG PILE AND FLEXIBLE PILE COMPOSITE FOUNDATION SUCH AS PERFORMANCE SIMULATION}

\section{A. Model Establishment and Model Parameter Selection}

In practical engineering, the free state of rigid pile body strength is usually long between C20 C40, its strength grade is $\mathrm{C} 20$ concrete deformation modulus of $2.55 \times 104 \mathrm{MPa}$, strength grade of C30 concrete modulus of deformation of $3.00 \times 104 \mathrm{mpa}$, the strength grade of C40 concrete modulus of deformation of $3.25 \times 104 \mathrm{mpa}$. The deformation modulus of soil-cement pile is usually between $1500 \mathrm{MPa}$ to 3000MPa.

Establish a freedom he just flexible numerical simulation model of single pile and pile group. The first step in the numerical simulation analysis is based on theory of load-settlement curve to simplify the numerical model is suitable for calculation. First of all, want to consider the size of the model, the scope of the foundation can be thought of as 
infinite body, size requirement is boundary constraints can not affect the simulation results. According to the experimental foundation to the treatment area, to determine the size of the model to $8 \mathrm{~m} \times 8 \mathrm{~m} \times 50 \mathrm{~m}$, the upper part of foundation soil is divided into loess powder clay thickness of $10 \mathrm{~m}$, lower part is divided into the thickness of the silty clay is $30 \mathrm{~m}$, adopts the hinge constraint boundary condition constraints. Considering the symmetry of the model, just under free state, the flexible pile model selection $1 / 2$ as a geometric model to calculate the selection. Among them, the flexible pile foundation model as shown in figure 1, flexible pile length of $10 \mathrm{~m}$, rigid pile foundation model as shown in figure 2, rigid pile length of $20 \mathrm{~m}$. More pile composite foundation is the selection of a quarter of the model as the calculation model, as shown in figure 4 . The three kinds of geometric parameters of the model, the model grid tumble and schematic diagram of the size of the model as shown in figure $1 \sim 6$.
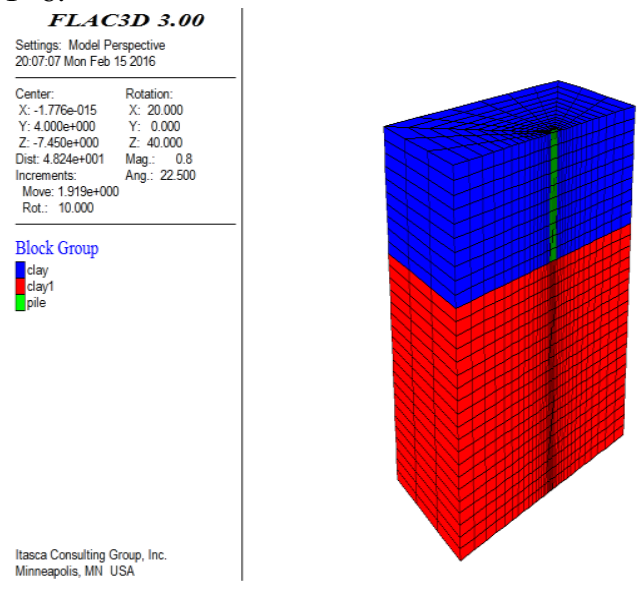

Figure 1. Flexible single pile static load
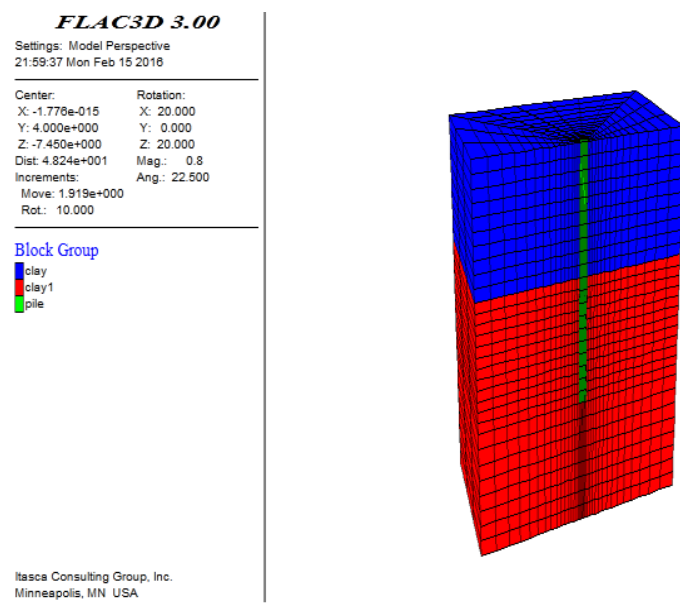

Figure 2. Rigid long pile static load

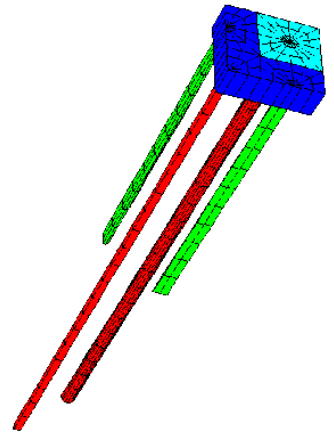

Figure 3. Rigid flexible length of pile
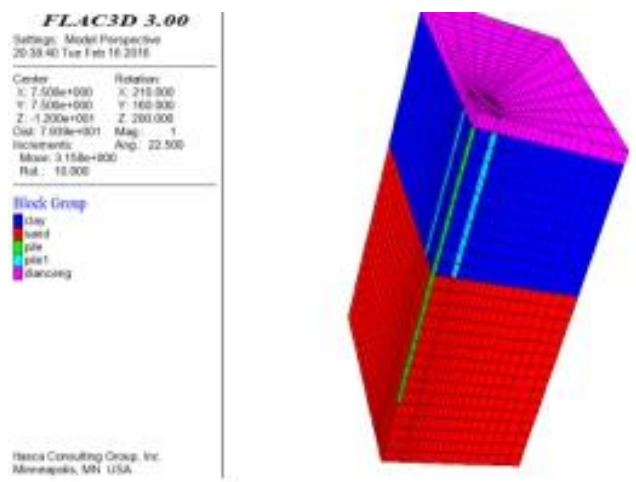

Figure 4. Rigid flexible composite foundation and cushion distribution

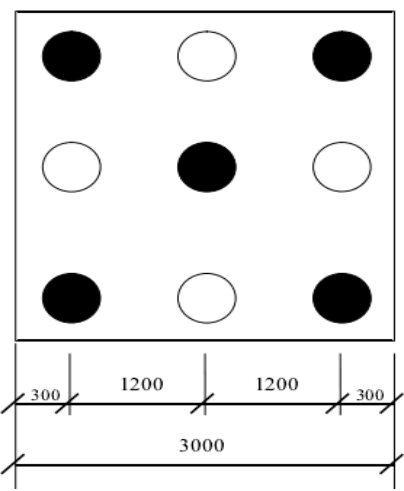

Figure 5. Schematic diagram of pile position

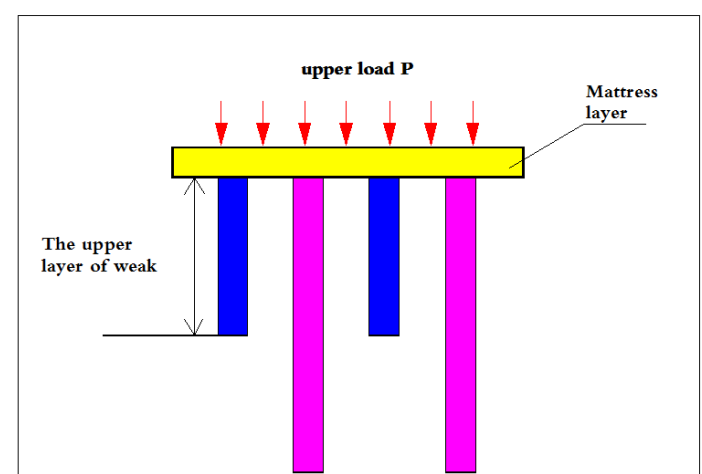

Figure 6. Schematic diagram of multi-pile composite foundation 
Pile and soil material is shown in table 1 . The pile by using the elastic model of isotropic soil, using Mohr-Coulomb plastic shell numerical model; contact surface of pile and soil by Mohr-Coulomb sliding model. Relative boundary conditions for the top boundary and free boundary and lateral horizontal sliding support (i.e. level constraints, the vertical movable bottom boundary), vertical sliding bearings (i.e. vertical constraint, horizontal moving).

\section{B. Contact Surface Parameter Selection}

Selection of pile soil contact surface parameters is relatively a very difficult to accurately determine the contact surface parameters to determine the specific value, you need to do a large number of tests, and consume huge manpower and material resources, if the test condition is not permitted, a lot of research the results of previous is can be used as a reference.

In this experiment, we put the contact surface of pile and soil is set to "soft" contact surface, which can reflect the deformation characteristics of the whole model. If the contact surface of the slip, then the bond strength of the corresponding value will not change, if it exceeds the tensile strength model set, then contact surface tension the strength is set to zero. You can take around "near the hard" discovery of stiffness and shear stiffness is 10 times:

$$
k_{n}=k_{x}=10 \max \left[\frac{\left(k+\frac{4}{3} G\right)}{\Delta Z \min }\right]
$$

Among them, the $\mathrm{k}$ is the corresponding bulk modulus, $\mathrm{G}$ is the shear modulus, pile soil contact surface normal direction is minimal size connection area. Clearly as you can see, calculates stiffness of pile soil contact surface to increase mainly by perpendicular to the interface of the decrease of the size of the smallest unit. In practical engineering, the commonly used prefabricated piles and bored piles, and of course there are other different types of pile. Pottyaondy and Acader research proves that the interface friction Angle between pile and soil is the key factor, friction force bearing characteristics of pile to clay take $=0.6$ to 0.7 (is an effective Angle of internal friction of pile soil) is more appropriate. In this case contact parameters as shown in table 2 .

\section{Long Short Pile Length, Long Piles and Rigid Flexible Pile}

According to the numerical simulation and the length of short pile length, long piles and rigid flexible pile Q-S curve theory comparison, figure 7 9 shows, test curves and simulation curves are basically consistent, indicating that the model is reasonable and can provide the basis for the study of the problem.

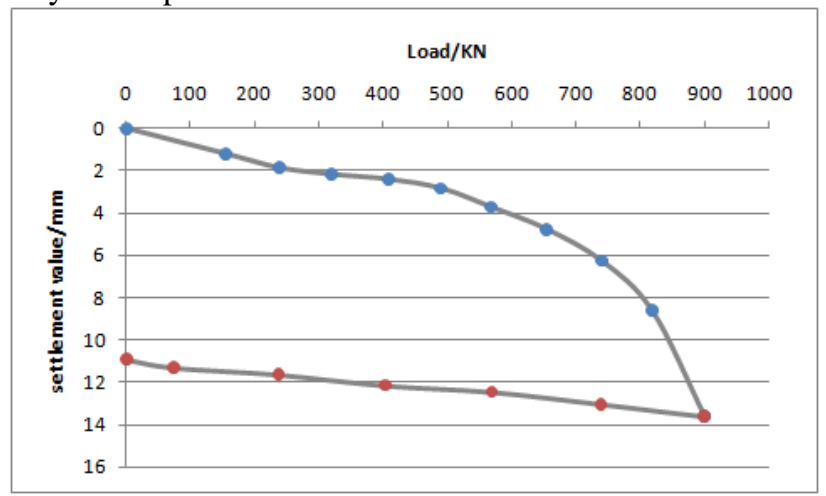

Figure 7. Q-S of rigid long piles under free condition

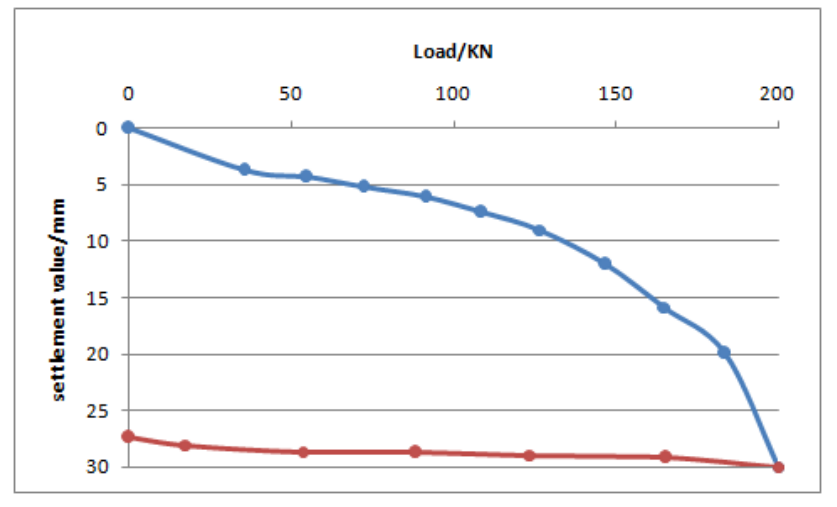

Figure 8. Q-S of flexible section pile under free condition the comparison of simulation

TABLE I. Pile AND Soil Material Parameters

\begin{tabular}{ccccccccc}
\hline Material & model & E/MPa & $\boldsymbol{V}$ & $\mathrm{C} / \mathrm{KPa}$ & $\boldsymbol{\nabla} / /^{\circ}$ & $\boldsymbol{F} / /^{\circ}$ & $\boldsymbol{\Sigma} / \mathrm{cm} / \mathrm{s}$ & $\boldsymbol{F} / \mathrm{KN} / \mathrm{m}^{3}$ \\
\hline concrete pile & Elastic model & 2000 & 0.3 & - & - & - & - & 25 \\
mixing pile & Elastic model & 1500 & 0.32 & - & - & - & - & 23 \\
Loess like clay & Mohr-Coul & 10 & 0.35 & 30 & 21.8 & 0.1 & $1.78 \times 10^{7}$ & $1.78 \times 10^{7}$ \\
silty clay & Mohr-Coul & 26 & 0.33 & 28 & 18 & 0.1 & 18 \\
\hline
\end{tabular}

TABLE II. PARAMETERS OF CONTACT SURFACE

\begin{tabular}{ccccc}
\hline Contact type & $\mathrm{Kn} / \mathrm{kn}$ & $\mathrm{Ks} / \mathrm{kn}$ & Fric & $\mathrm{Coh} / \mathrm{Pa}$ \\
\hline Soil pile -soil & $1.8 \times 107$ & $1.8 \times 10^{7}$ & 0.4 & $30 \times 10^{6}$ \\
Contact surface & $1.78 \times 107$ & $1.78 \times 10^{7}$ & 0.5 & $28 \times 10^{8}$ \\
\hline
\end{tabular}




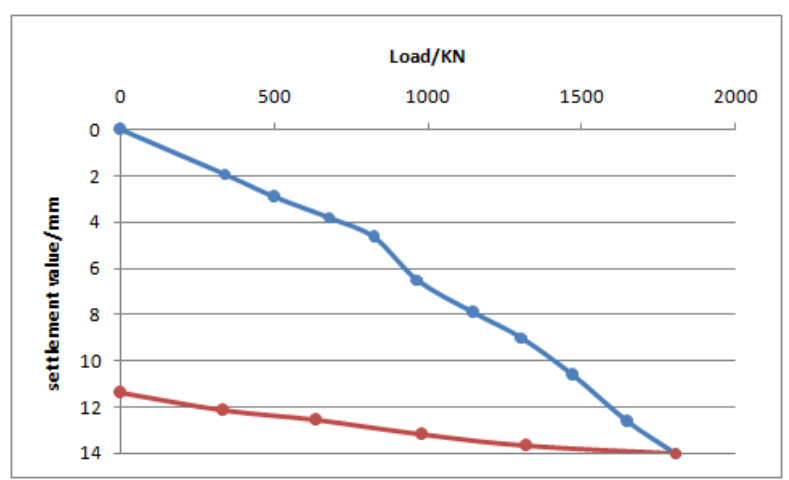

Figure 9. Q-S multi pile composite foundation test

\section{LONG ShORT PILE LENGTH, Long PILES AND RIGID FLEXIBLE PILE STRESS, DEFORMATION ANALYSIS}

\section{A. Axial Force Distribution of Pile}

According to the test data of the model built in the last section, we can get the curve of the axial force of the pile under the load at all levels, as shown in Figure 10.

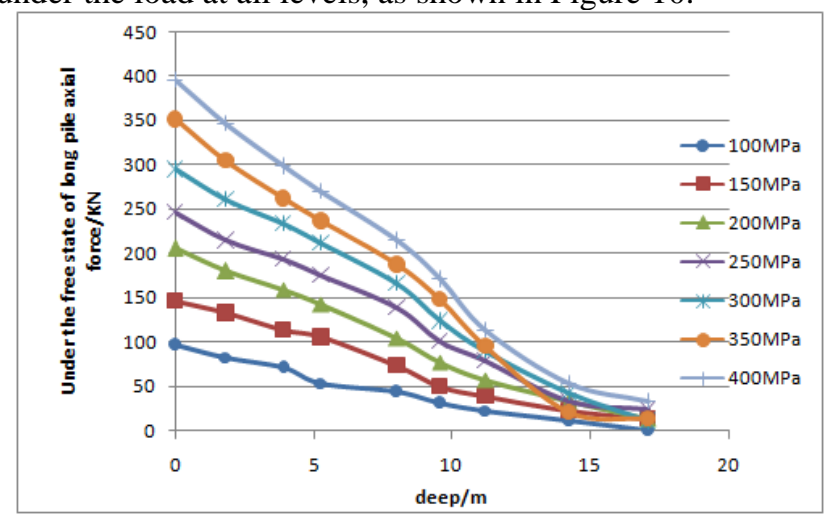

Figure 10. Rigid long pile axial force distribution under free condition

For the free state of rigid pile, the axial force can be seen in each load under the action of axial force with the depth increasing trend is gradually decreased, at the bottom of the pile axial force of pile is 0 , which indicates that the pile bottom load sharing, in each load added by according to the linear attenuation, axial force.

For the free state by the flexible pile, axial force distribution of 3.2 can be seen that the increase in axial force in each stage loading with pile depth tendency, the exponential decay of the same, at the bottom of the pile axial force of pile is 0 .

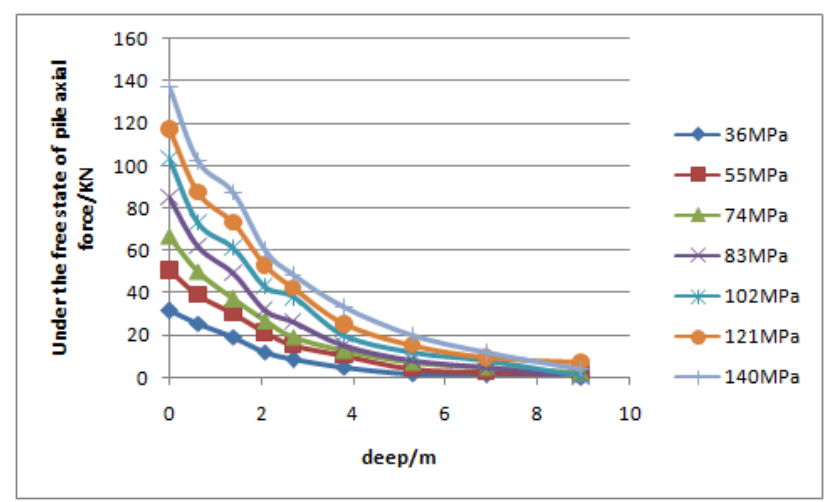

Figure 11. Axial force distribution of flexible short pile under free condition

\section{B. Deformation Analysis}

Figure 12 and 13 respectively in different pile composite foundation soil displacement. The single pile composite foundation, the upper reinforcement soil compression is the main part of foundation settlement, because the loading plate width is smaller, the affected depth is limited. For the rigid pile composite foundation, the pile bottom requirements on bearing layer, and because the bearing layer of high strength, small amount of compression, so the amount of compression of the substratum is negligible.

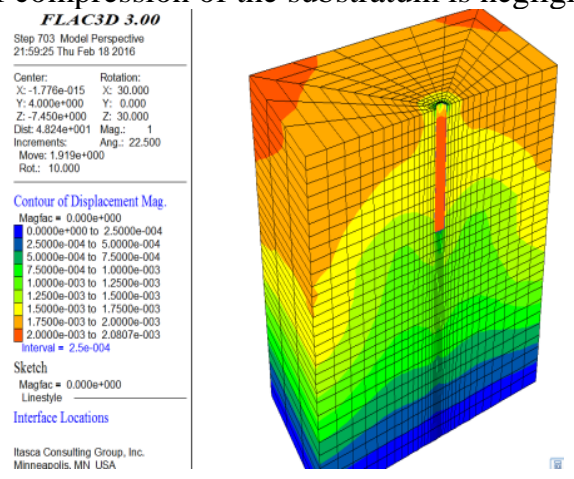

Figure 12. Displacement cloud of flexible

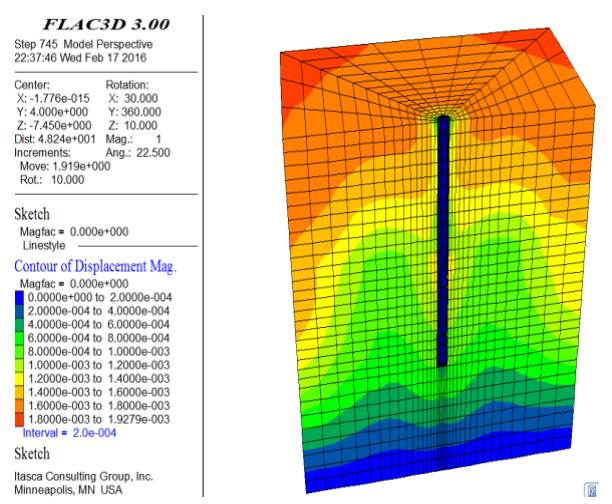

Figure 13. Displacement cloud of rigid longshort piles under free condition 


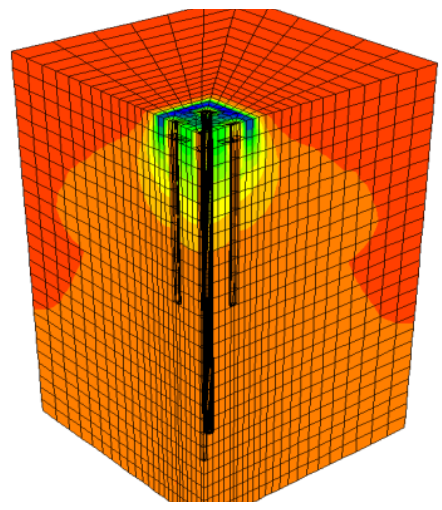

Figure 14. Displacement contour of multi pile composite foundation

Figure 14 is a multi pile settlement of composite foundation under the load generated by the composite foundation with single pile compared to the free state can be seen in the same load, when the displacement of multi type pile composite foundation settlement to the stability, settlement it should be much smaller than the free the state of single pile composite foundation. The same as the single pile composite foundation, the total settlement of multi type pile composite foundation is mainly concentrated in the upper part of the reinforced soil.

\section{CONCLUSION}

(1) In the actual engineering design, the selection of long pile materials, from the economic perspective, the rigidity of pile body modulus without setting a very high, but to meet the basic requirements of a pile, the pile strength of rigid long piles is not too low.

(2) The increase of the modulus of the lower lying layer can effectively reduce the difference of the foundation settlement and settlement.

(3) Compared with the homogeneous foundation, the high stress area in the composite foundation moves down, and the high stress value is reduced, the influence of the additional stress is deepened, can achieve very good effect, the economic effect is obvious.

\section{REFERENCE}

[1] K and RandolPh M F Horikoshi, dry Teng Jun, Deng Anfu translation, the method of determining the soil stiffness of rectangular raft foundation, underground space, 1999, 19 (3).

[2] RoweR.K series, reinforced embankment on soft clay, the third National Conference on synthetic materials special report, 1992.

[3] Lingxiang, experience and design method of pile foundation in Shanghai, East China Electric Power Design Institute, 1979.

[4] Guo Zhiqiang, Zhang Xiaozhe, Liu Fengjun and so on, combined type composite foundation engineering example, engineering survey, 2003 (2).

[5] Yan Mingli, Wang Mingshan, Yan Xuefeng et al. Study on the design and calculation method of multi pile composite foundation. Chinese Journal of geotechnical engineering, 2003, 25 (3).

[6] Zhou Dequan, Zhang Ke, Liu Hongli. Several key points, construction technology, 2004, 36 (3) for the rational setting of cushion and pile in composite pile composite foundation.

[7] Bransby, M.F. Springman, S.M. 3D finite element modeling of pile groups aduacent to surcharge.

[8] Mao, Gong Xiao. The utility of pile composite foundation of flexible cushion of rock and soil mechanics [J]. 1998, 19 (2): 67-73. 